\title{
Kokemuksia taidehistorian opiskelijoiden ja taidemuseon yhteistyo̊stå: Otto W. Furuhjelmin kokoelma
}

Hanna Kivelä \& Anna Vuolanto

Helsingin kaupungin taidemuseon (HAM) kokoelmiin liitettiin vuonna 2015 Venäjän armeijan kenraaliluutnantti Otto Wladimir Furuhjelmin (1819-1883) taidekokoelma. Kokoelma oli päätynyt testamenttilahjoituksena alun perin Helsingin kaupungin haltuun pääosin vuonna 1895. Se oli ensimmäinen kaupungille lahjoitettu taidekokoelma, jonka oli tarkoitus tulla osaksi perustettavaa kaupunginmuseota.

Tässä kirjoituksessa esitellään Helsingin yliopiston taidehistorian oppiaineessa kevättalvella 2018 järjestetyn Vanhan taiteen seminaarin ja Helsingin kaupungin taidemuseon HAMin yhteistyöhankkeena toteutettua O.W. Furuhjelmin kokoelman tutkimusprojektia ja siinä heränneitä ajatuksia. Kurssin vetäjänä toimi yliopistonlehtori Elina Räsänen, ja kurssilla tarkasteltiin kokoelmaa sekä kokonaisuutena että keskityttiin tiettyihin yksittäisiin teoksiin. Tavoitteena oli käytännönläheisyys, ongelmanratkaisu sekä opiskelijoiden perehdyttäminen tutkimustyön konkreettiseen tekemiseen. Pidemmän tähtäimen toiveena oli teosten saattaminen jälleen myös yleisön nähtäville. Kurssin yhdeksästä opiskelijasta kukin myös valitsi kokoelman 58:sta maalauksesta yhden teoksen tarkasteltavakseen. Teosten esivalintaa oli tehty museon amanuenssin Leena Mattelmäen kanssa.

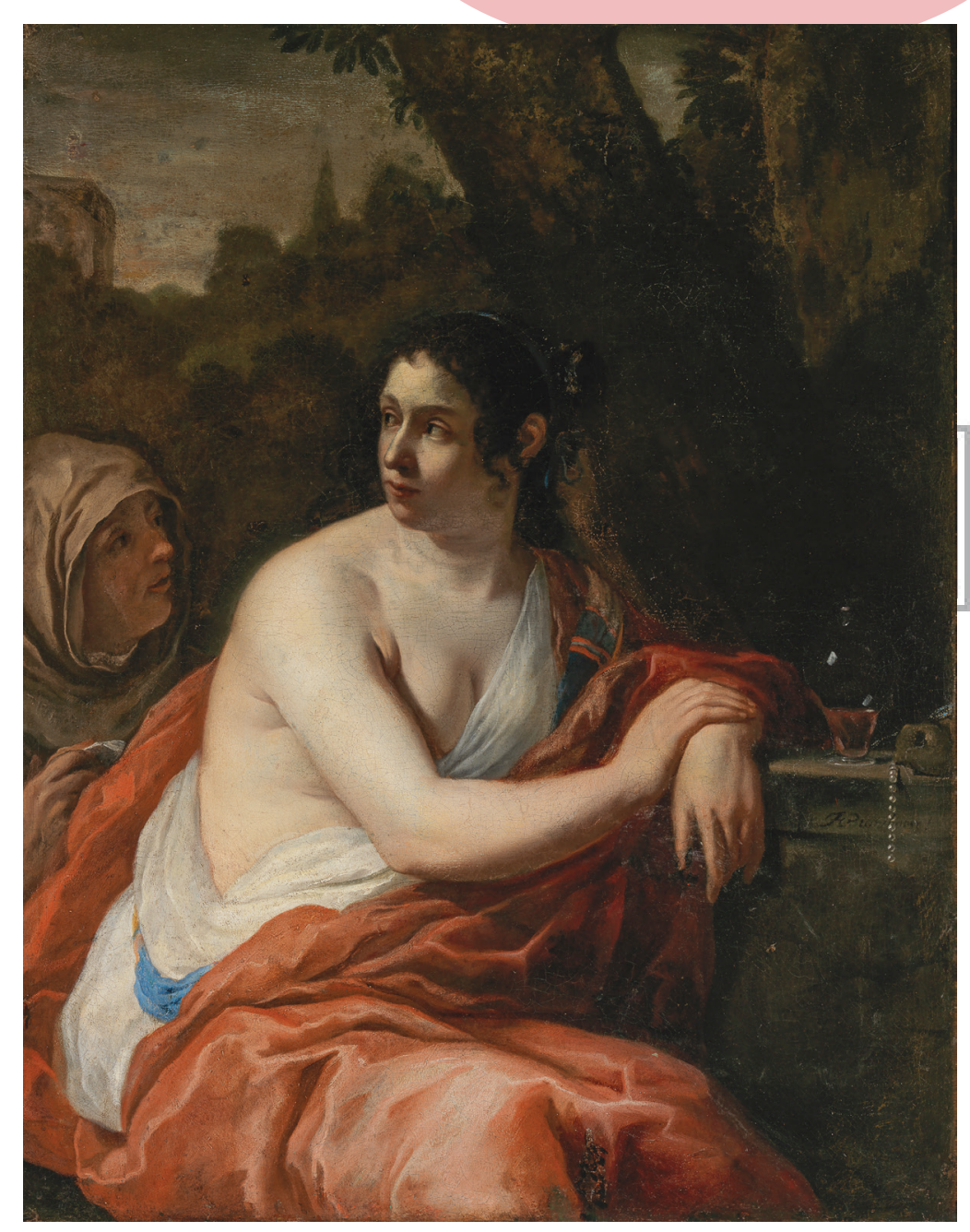

Kuva 1. Jan Gerritsz van Bronckhorst, Batseba, öljy kankaalle, 1650-luku. Otto W. Furuhjelmin kokoelma. (C) HAM Helsingin taidemuseo/ kuvaaja Hanna Kukorelli. 


\section{Furuhjelmin kokoelman vaiheita}

Turussa syntynyt Otto W. Furuhjelm oli luonut sotilasuraa Venäjällä. Aikakaudelle tyypillisenä yläluokan harrastuksena hänkin keräili taidetta. Ajan hengen mukaisesti kokoelmiin tuli sisältyä niin vanhaa alankomaalaista kuin italialaista ja ranskalaistakin taidetta. Kokoelmasta katsauksen vuonna 1954 kirjoittaneen Antero Sinisalon mukaan Furuhjelmin kokoelmaa voi pitää melko tyypillisenä ajan venäläisenä taidekokoelmana. ${ }^{1}$ Sinisalo kirjoitti kokoelmaa koskevan laudatur-esitelmänsä kartoittaakseen kokoelman arvoa ja kiinnostavuutta, sillä museon tilat olivat menossa remonttiin ja teoksia oltiin siirtämässä varastoon.

Kokoelman suurimmat teosryhmät ovat venäläiset maalaukset (Sinisalon mukaan noin viidesosa), pääosin 1800-luvulta, ja alankomaalainen 1600-luvun taide (samoin noin viidesosa). Lisäksi kokoelmassa on muutama vanhempi italialainen ja ranskalainen maalaus sekä 1700- ja 1800-lukujen saksalaista maalaustaidetta. ${ }^{2}$ Teosten attribuointi ei kuitenkaan ole kovin yksiselitteistä. Kokoelman mukana tullut, ilmeisesti Furuhjelmin veljen laatima ranskankielinen luettelo on ainoa dokumentti, jossa tietoja teosten tekijöistä ja proveniensseista on olemassa. Pietarissa asunut kenraaliluutnantti Furuhjelm harrasti myös Suomen historiaa - tosin tämä ei erityisesti taidekokoelmassa näy. Se lienee kuitenkin motivoinut häntä tekemään lahjoituksen synnyinmaansa Suomen suuriruhtinaskunnan pääkaupungille. Furuhjelm hankki teoksia kokoelmaansa pääasiassa Pietarin huutokaupoista, lukuun ottamatta joitakin ulkomaanmatkojen aikana hankkimiaan maalauksia.

Furuhjelm esitti testamentissaan toiveen kokoelman esillepanosta tulevaan museoon "kenraali Furuhjelmin saliin"3. Ennen kaupunginmuseon perustamista maalauksia oli esillä myös Ateneumissa vuosien 1895-1911 välillä. ${ }^{4}$ Tämän jälkeen kokoelman teoksia oli vielä ainakin 1950-luvulla kaupunginmuseon näyttelyssä.

Sittemmin kokoelma on saanut osakseen vain vähän huomiota, ja vain yksittäisiä teoksia mainitaan näyttelyiden yhteydessä vuosikymmenten varrella. Vuoden 2015 siirron tarkoituksena kaupunginmuseosta HAMiin olikin saada kokoelman teokset niiden vaatiman asiantuntemuksen ja kansainvälisten verkostojen piiriin. Samoin ajateltiin, että HAM voisi tarjota tilat teosten esillepanoon.
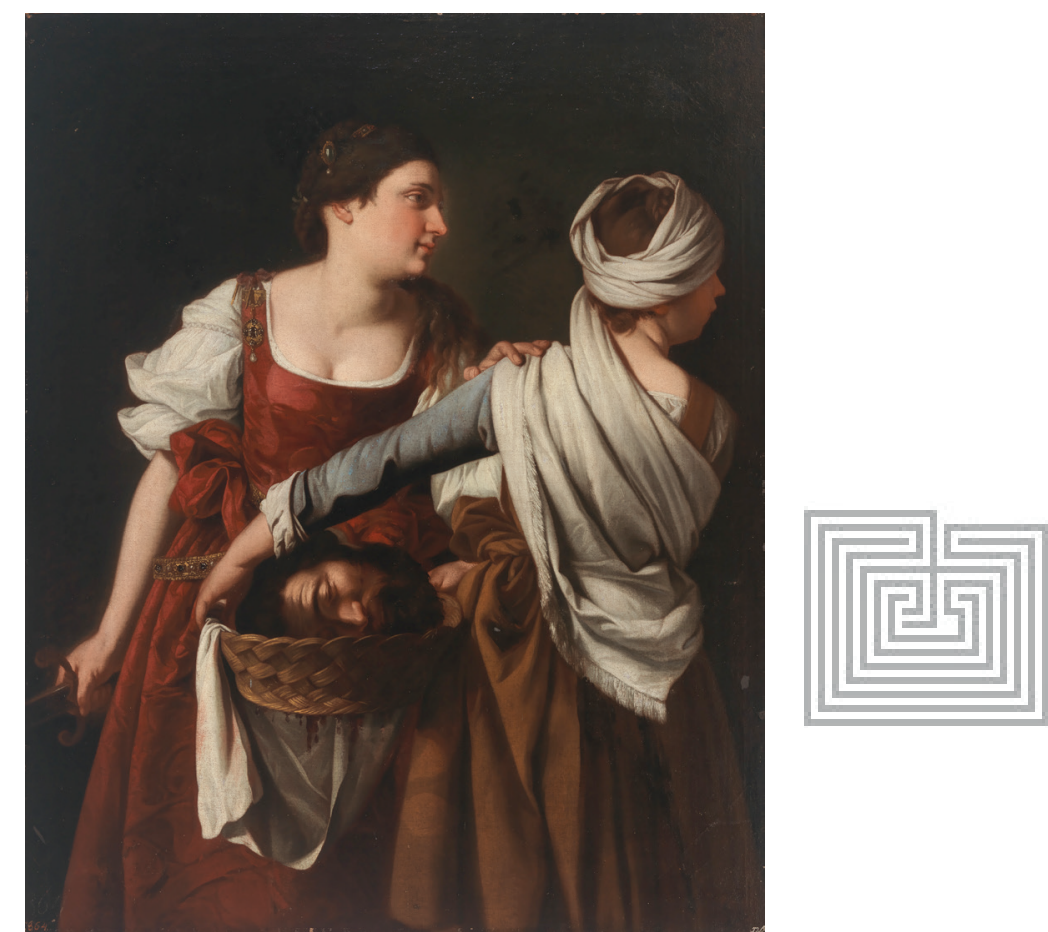

Kuva 2. Pierre Mignard, Juudit ja palvelijatar, öljy kankaalle, 1630-1650. Otto W. Furuhjelmin kokoelma. CHAM Helsingin taidemuseo/ kuvaaja Hanna Kukorelli.

Tutkimusta on aikaisemmin kohdistunut pääasiassa muutamiin yksittäisiin teoksiin. Kokoelman parhaiten tunnettuja teoksia lienevät Jan Gerritsz van Bronckhorstin Batseba 1650-luvulta, sekä Juudit ja Holofernes -aihetta käsittelevä, Orazio Gentileschin teoksen kopio Juudit ja palvelijatar. Edellä mainittua tutki 1980-lu- 
vulla alankomaalainen Thomas Döring, joka käsitteli teosta vuonna 1988 julkaistussa artikkelissa. ${ }^{5}$ Kurssilla tätä koskevaa selvitystyötä teki Maria Tuovinen. Jälkimmäisestä on vastikään viime vuonna kirjoittanut taidehistorioitsija Synnöve Malmström, joka esitteli tutkimuksensa tuloksia kurssin opiskelijoille teoksen äärellä. Hän ajoitti teoksen aikavälille 1630-1650 jatkaessaan taidemuseon pyynnöstä selvitystyötä, jota kaupunginmuseon tutkija Kerttuli Wessman oli tehnyt jo 1980-luvulla. ${ }^{6}$ Malmströmin tutkimus olikin yksi tärkeimmistä esimerkeistä, kun aloitimme vuoden 2018 alussa työskentelyn kokoelman parissa.

\section{Kurssilla tehtyä tutkimusta}

Tähän tekstiin olemme nostaneet muutaman niistä teoksista, joita kurssilaiset ottivat lähempään tarkasteluun, ja tiedot perustuvat opiskelijoiden tekemiin, kurssin lopussa palauttamiin tutkimusraportteihin. Valitsimme kolme teosta, muotokuvakopion, asetelman ja maiseman, joita pidimme keskeisinä aikakauden kokoelman kartuttamisen näkökulmasta. Ne myös herättivät kurssilla eniten keskustelua. Erityisesti keräilijyys suhteessa yhteiskunnallisiin ihanteisiin sekä taiteen asema, arvostus ja sille määritellyt tehtävät nousivat teosten kohdalla esille.

Työt aloitettiin vierailulla kokoelmavarastoon kokoelmapäällikkö Elina Leskelän johdolla, jolloin opiskelijat pääsivät tarkastelemaan valittuja teoksia lähietäisyydeltä, edestä ja takaa.
Varsin monien teosten alkuperän epävarmuus sekä lahjoituksen mukana tulleet vähäiset tiedot teosten tekijöistä toivat keskusteluun omasta ajastamme poikkeavan näkemyksen koskien alkuperäisyyden vaatimusta ja taiteen tehtävää. Tunnettujen tekijöiden teosten kopiot olivat 1800-luvulla tapa

Kuva 3. Teosten tarkastelu alkoi varastolla. Katseiden kohteena itse kenraali Furuhjelm. @ Anna Vuolanto.

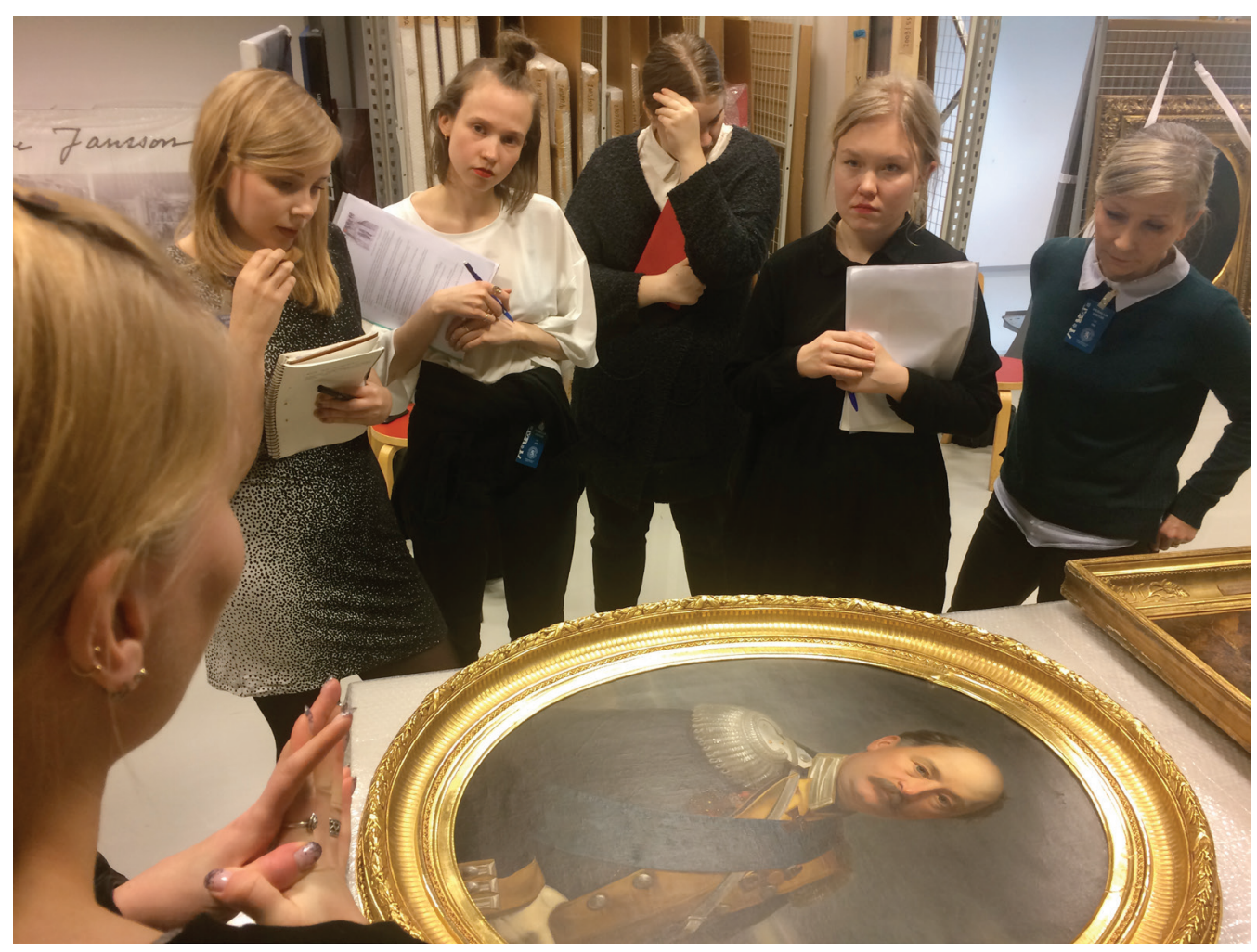




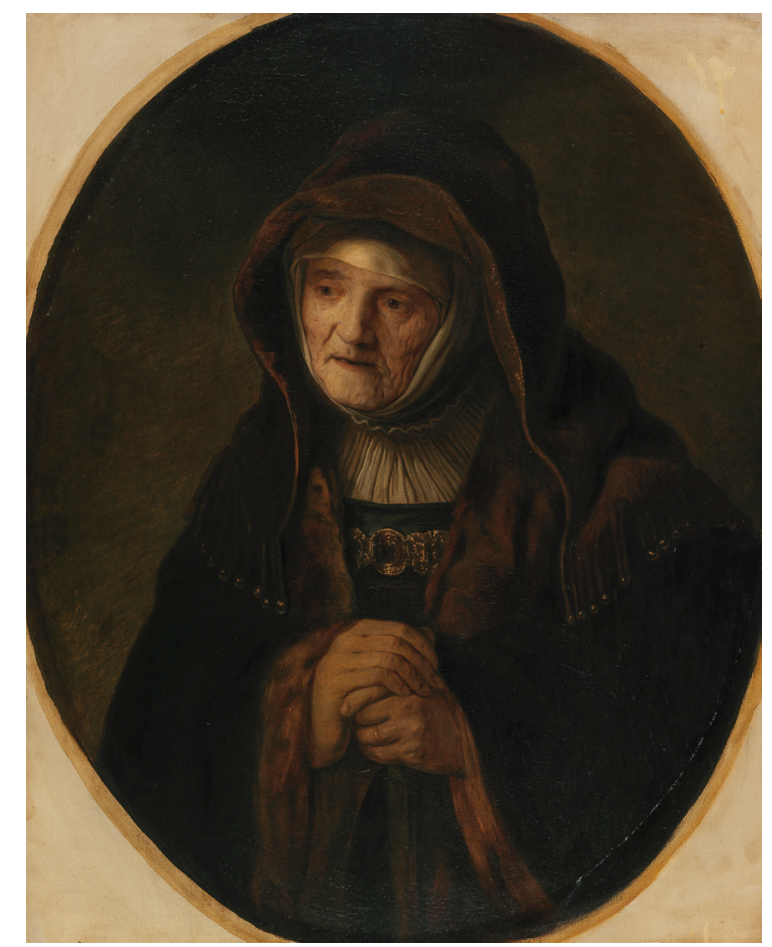

Kuva 4. Tuntematon tekijä, Profeetta Hanna (Rembrandtin äiti), kopio, öljy kankaalle, 1800-luku. Otto W. Furuhjelmin kokoelma. CHAM Helsingin taidemuseo/ kuvaaja Hanna Kukorelli

tutustua vanhojen mestareiden töihin. Samoin ne olivat myös merkittävä osa kuvataideopetusta. Toisaalta keräilyn motiivina saattoi yhtä hyvin olla yksityisen keräilijän mahdollisuus tuo-

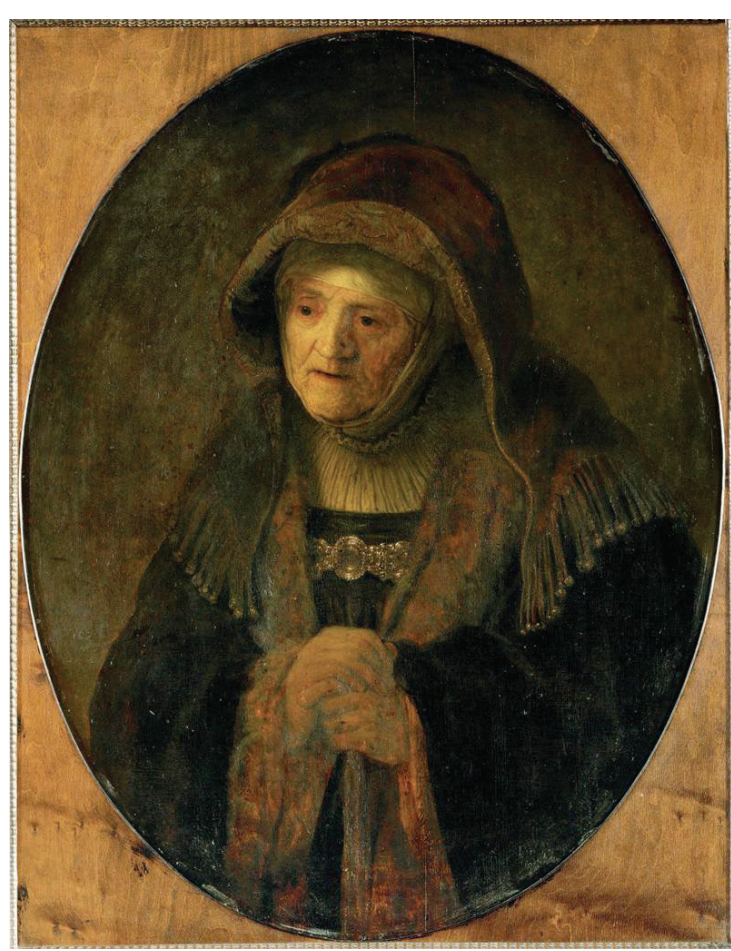

Kuva 5. Rembrandt, Profeetta Hanna (Rembrandtin äiti), 1639. Öljy tammipannoolle, 79,5 x 61,5 cm. Kunsthistorisches Museum, Wien. Kuvalähde: Art Stor.

da ulkomaanmatkoiltaan edes häivähdys siitä elämyksestä, minkä taide Euroopan ytimessä saattoi synnyttää - tai siitä statuksesta, jota taideteos saattoi keräilijän kohdalla alleviivata.
Irene Riihimäki, joka on tutkinut pro gradussaan Helsingin yliopiston piirustuslaitoksen historiaa, pohti kopioiden merkitystä osana taideopetusta tutkiessaan kokoelmaan kuuluvaa Rembrandt-kopiota Profeetta Hanna (Rembrandtin äiti). Jäljennökset Rembrandtin teoksista olivat 1800-luvulla suosittuja. Alkuperäinen teos on maalattu vuonna 1639 , ja se on Wienin Kunsthistorisches Museumissa, jossa Furuhjelmin kokoelman kopio on todennäköisesti maalattu. Furuhjelm myös osti teoksen Wienistä. Kyseessä on mahdollisesti harjoitus-, opinnäyte- tai jopa mestarityönäyte, kuten Riihimäki kiinnostavasti tulkitsi. Taidokkaasti maalattu muotokuvakopio sisältää hupaisan yksityiskohdan, joka paljastaa kopioijan katsoneen alkuperäistä liian läheltä: vanhan naisen kävelykepin kahva muistuttaa kopiossa pikemminkin sormea.

1800-Iuvulla taiteen keräilijän kokoelmassa tavallinen teostyyppi oli asetelmamaalaus. Asetelmat olivat usein kokoelmien edullisimpia maalauksia, joita siihen vielä voitiin uskottavasti liittää. Susanna Serlachius tutki todennäköisesti 1800-luvulta peräisin olevaa asetelmaa, johon on kuvattu kaloja, juureksia, purkillinen munia ja astioita. Ko- 
konaisuus on melko sekalainen, eikä varsinaisesti viittaa yhteen ateriakokonaisuuteen. Piilomerkityksetkään eivät ole kovin ilmeisiä. Serlachius päätyi katsauksessaan tulkintaan, jonka mukaan teos edustaa saksalaista porvarismaalausta. Sellaisen tarkoituksena oli pikemminkin tuoda yksityiskohdillaan esille omistajansa varallisuutta kuin filosofisia katoavaisuuden teemoja.

Kuva 6. Tuntematon tekijä, Asetelma (Nature morte), öljy kankaalle, 1800-luku. Otto W. Furuhjelmin kokoelma. CHAM Helsingin taidemuseo/ kuvaaja Hanna Kukorelli

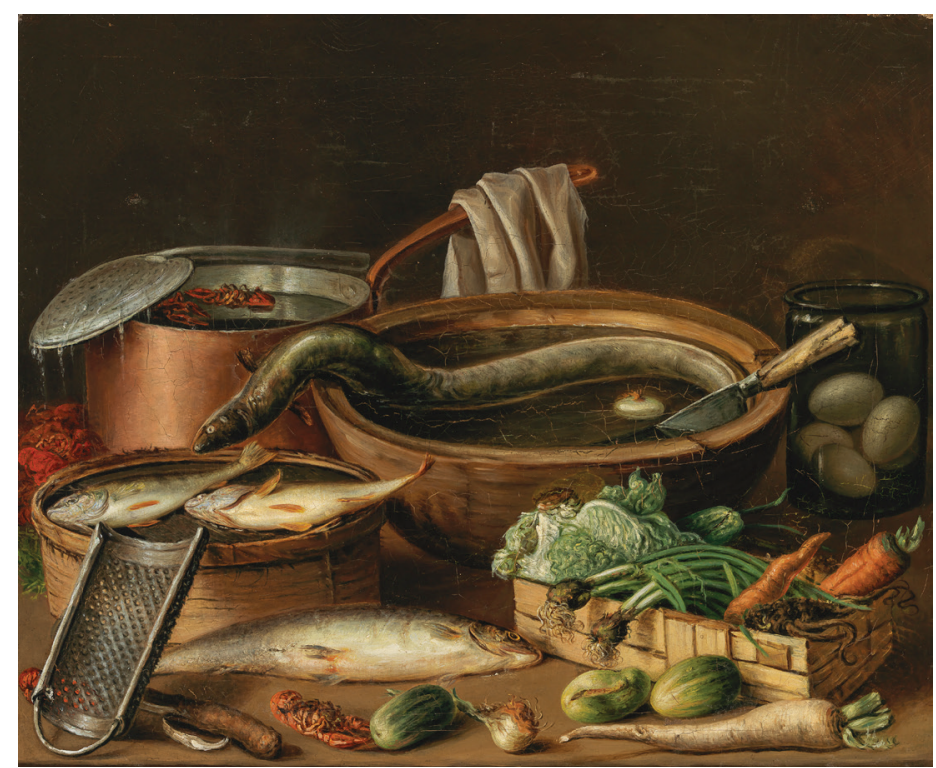

Kokoelmassa ovat hyvin edustettuina niin metsästysaiheet kuin merimaalaukset, lähinnä venäläisten taiteilijoiden teoksina. Nämä kertonevat Furuhjelmin omista mieltymyksistä, joka herättää miettimään sekä itse keräilijän motiiveja että yksittäisten teosten merkityksiä kokoelman osina. Tarkasteltaessa yksittäisiä teoksia suhteessa koko kokoelmaan, onkin mielenkiintoista pohtia, miksi juuri kyseinen teos on hankittu tai mikä sen "tarve" kokoelmassa on. Kuuluvatko metsästys- tai asetelma-aiheet ruokasalin sisustukseen tai halusiko keräilijä juuri merimaiseman työhuoneeseensa?

Furuhjelmin keräämät taideteokset olivat hänen leskensä Olga Alexandrovnan hallussa tämän kuolemaan vuoteen 1895 saakka. Puolison roolista kokoelman muodostamisessa ei tiedetä mitään, mutta teokset olivat varmasti arvokas osa pietarilaiskodin sisustusta muiden arvoesineiden ohella. Ivan Aivazovski oli jo omana aikanaan arvostettu taiteilija, ja Furuhjelmin kokoelmassa hänen nimellään kulkee teos Kultainen sarvi. Helene Lillgäls tutki teosta vertailemalla sitä muihin taiteilijan teoksiin sekä Konstantinopolista/Istanbulista otettuihin valokuviin. Aivazovski oli hyvin tuottelias taiteilija, ja hänen nimiinsä on kenties melko turvallista laittaa teos jos toinenkin: itse hän sanoi maalanneensa yli 6000 teosta. Tarkastelunsa lopputuloksena Lillgäls esitti arvion, jonka mukaan teosta ei ainakaan ole maalattu paikan päällä Kultaisen sarven rannalla. Samoin siinä ei myöskään ole taiteilijan signeerausta, toisin kuin hänen teoksissaan yleensä. Myös teoksen hyvin puutteelliset ja heikkolaatuiset yksityiskohdat herättävät vähintäänkin kysymyksen aitoudesta, Lillgäls esitti. Aivazovski saattoi maalata yhdistelemällä yksityiskohtia eri paikoista, mutta teokset ovat poikkeuksetta runsaita yksityiskohdissaan.

Esiin nousseita tekijänimiä pohdittiinkin seminaaritapaamisissa useaan kertaan. Alkuperäinen teos on helppo asettaa arvokkaammaksi, mutta myös "aidot kopiot" ovat itsessään teoksia. Mikä on aitoa, kenen kädessä sivellin on ollut, vai riittääkö, että ollaan tietyn taiteilijan vaikutuspiirissä? Furuhjelmin kokoelman kontekstissa aitoutta tärkeämmäksi nousee mielestämme kokoelman tarkasteleminen 1800-luvun kansainvälisen Pietarin kontekstissa. On kiinnostavaa nähdä kokoelma kertomassa keräilijän sosiaalisesta, taloudellisesta ja kulttuurisesta aika- 
laistodellisuudesta. Teokset todennäköisesti riippuivat Furuhjelmin kaupunkihuoneiston seinillä, ja sitä tarkastelivat hämärässä kynt-

tilöiden, soihtujen tai öljylamppujen valossa hänen vieraansa, sotilasvirkamiehet, kauppiaat, aateli.

Kuva 7. Ivan Konstantinovits Aivazovski?, Kultainen sarvi, öljy kankaalle, 1850-luku. Otto W. Furuhjelmin kokoelma. CHAM Helsingin taidemuseo/ kuvaaja Hanna Kukorelli.

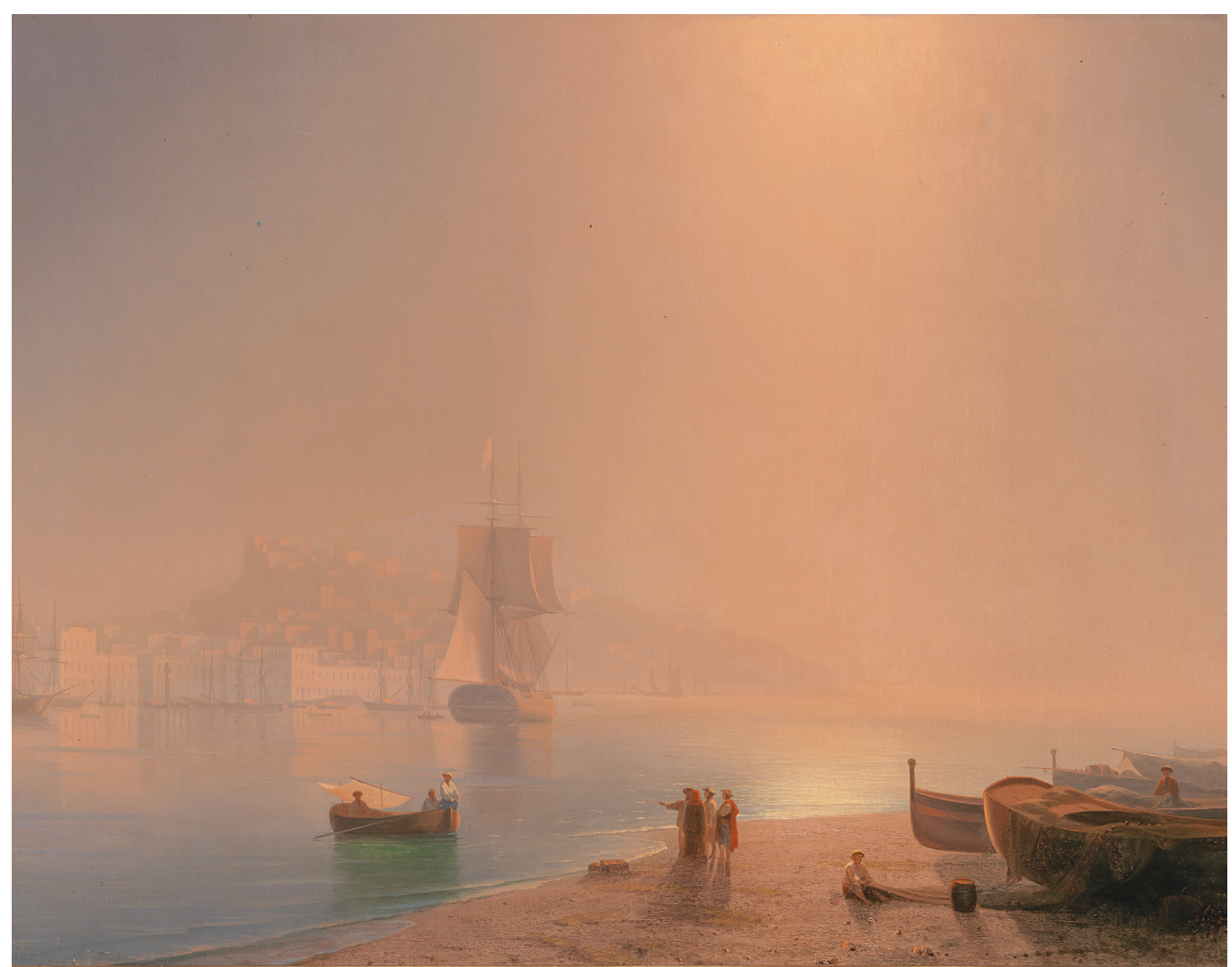

Kurssin opiskelijat tekivät paljon yksityiskohtaista selvitystyötä valitsemistaan teoksista. Kirjallisen tutkimustyön lisäksi opiskelijat pääsivät tutustumaan museon henkilökunnan avustuksella fyysisesti teoksiin. He etsivät niistä mahdollisia johtolankoja, kuten kehysten taakse piilotettuja huutokauppojen leimoja ja jälkikäteen tehtyjä korjailuyrityksiä. He tutkivat myös kehystyksiä, joiden arveltiin peittävän signeerauksia. Yhteistyö yliopiston ja taidemuseon välillä tarjosi taidehistorian opiskelijoille konkreettisen mahdollisuuden päästä perehtymään tutkijan työhön. Kurssin opiskelijoiden töiden pohjalta kootaan HAMin verkkosivuille näyttely.

Kurssin osallistujat: lida Arvola, Emmi Halmesvirta, Petra Hanski, Saila Leskinen, Helene Lillgäls, Irene Riihimäki, Susanna Serlachius, Saana Tuomela, Maria Tuovinen.

\section{Viitteet}

1 Antero Sinisalo, Esitelmä Helsingin yliopiston taidehistorian laitoksen laudatur-seminaarissa 8.6.1954 (Helsingin kaupungin taidemuseo HAMin arkisto), 2; kokoelmasta ks. myös Catalogue des Tableaux de la Collection du Général O. Furuhjelm (1883) (Helsingin kaupungin taidemuseo HAMin arkisto). 
2 Sinisalo, "Furuhjelmin kokoelma", 2.

3 Helsingfors stadsfullmäktiges trycta handlingar.

N:o 24 (1895) (Helsingfors Tidnings- \& Tryckeri-

aktiebolagets tryckeri, Helsingfors), liite 2. "Hvarvid, $i$

händelse stadens representerar icke anse det såsom

en oblygsamhet å mina sida, jag skulle önska att helst

en af sagde musei salar skulle benämnas General

Furuhjelms sal".

4 Ibid, liite 1; Sinisalo, "Furuhjelmin kokoelma", 4

5 Thomas Döring, "Between Caravaggism and

Classicism: Bathsheba by Jan Gerritsz. and Johannes

van Bronchorst", The Hoogsteder[-Naumann]

Mercury, no 7 (1988): 51-67.

6 Malmström, Synnove. "Judit och tjänarinnan med

Holofernes huvud". Tutkimusraportti 10.11.2017,

tekijöiden arkisto.

HuK Hanna Kivelå on Helsingin yli-

opiston taidehistorian ja museologian opiskelija. Hån toimi artikkelissa esi-

tellyllå kurssilla kurssiassistenttina.

HuK Anna Vuolanto on Helsingin yli-

opiston yleisen historian ja taidehisto-

rian opiskelija. Hän toimi artikkelissa

esitellyllå kurssilla kurssiassistenttina. 